\title{
Integrated modelling to aid strategic urban and regional planning
}

\author{
Rohan Wickramasuriya, Pascal Perez, Nam Huynh, Ashkan Masouman and Johan Barthelemy \\ ${ }^{a}$ SMART Infrastructure Facility, Faculty of Engineering and Information Sciences, University of \\ Wollongong, Wollongong NSW 2522 \\ Email:rohan@uow.edu.au
}

\begin{abstract}
Most of the current regional planning models rely on feed-forward trend analyses. However, economic, demographic, land use and infrastructure systems are far from isolated linear systems. They are in fact interdependent dynamic systems where a change in one systems impacts all other interdependent systems. Therefore, a change such as the addition of a new expressway to the transport network not only will bring changes in the transport system, but also in other systems like land use and demographic. Vision Illawarra is a modern tool that follows the system dynamics approach to incorporate these feedback loops between systems. Planners and policy makers can use Vision Illawarra to understand the holistic change a planning or policy decision will bring to the regional setting, thus enabling them to make smart strategic decisions for the benefit of the region.
\end{abstract}

Keywords: Urban planning, land use, transportation, input-output model, synthetic population 


\section{INTRODUCTION}

Strategic regional planning concerns long term projects that aim to bring about sustainable development (United Cities and Local Governments, 2010). This is often a challenging undertaking as it requires careful balancing of competing priorities such as accessible and affordable transportation, innovative and productive economy, and protected natural environments (Geerlings and Stead, 2003). It is crucial to understand dynamic interactions between different sub-systems like land use, transportation and economy in an urban or regional landscape, and how an action that alters one sub-system might impact other interdependent systems. When this knowledge is available, it is possible to make decisions that maximise the overall benefits for the urban or regional area of concern.

Although modelling can be used to explore the cascading impact of a change in complex systems like urban landscapes, many current planning models rely on feed-forward trend analysis. Such models fall short of providing right insights into complex systems where dynamic multiway interactions govern the evolution of the whole system. Moreover, these trends are based on demographic or economic assumptions that lock-in regional growth into predefined pathways. A weaker initial assumption can result in a less plausible evolution in other aspects of the regional development. Regional planning models need to follow observed patterns to become useful. To this end, such models should incorporate land use, transport, economic and demographic factors that interact with each other and co-evolve in a simulation environment (van Delden et al, 2011).

We have embarked on a project that aims to develop an integrated model encapsulating five interconnected modules: land use, transportation, econometric input/output model (EC-IO), synthetic population (SP) and utilities. This paper discusses the ongoing work on developing, integrating and validating the dynamic simulation model that is codenamed 'Vision Illawarra'.

\section{METHODS}

The Illawarra, a coastal region located south of Sydney in Australia, is our study area that consists of three Local Government Areas (LGAs): Wollongong, Shellharbour, and Kiama. These three LGAs occupy the coastal plain limited on the east by a forested escarpment, hence geographically well-demarcated as a region. According to the 2011 census (Australian Bureau of Statistics, 2011), the population of the Illawarra region stood at 288,036 persons.

\subsection{Models and Model Integration}

We use a sophisticated simulation platform called Geonamica (Hurkens et al., 2008) to build and integrate several modules namely, a cellular automata-based land use model, 4-step transportation model, regional interaction model, econometric input/output model and synthetic population (Figure 1). The land use model, transportation model and the regional model are collectively called Metronamica (van Delden and Hurkens, 2011), a land use modelling framework used by many countries and regions across the world. We populated these three models with appropriate data for the Illawarra region, and then performed calibration and validation. EC-IO model has been developed specifically for the Illawarra region. We utilised the methods developed by Huynh et al. (2013)

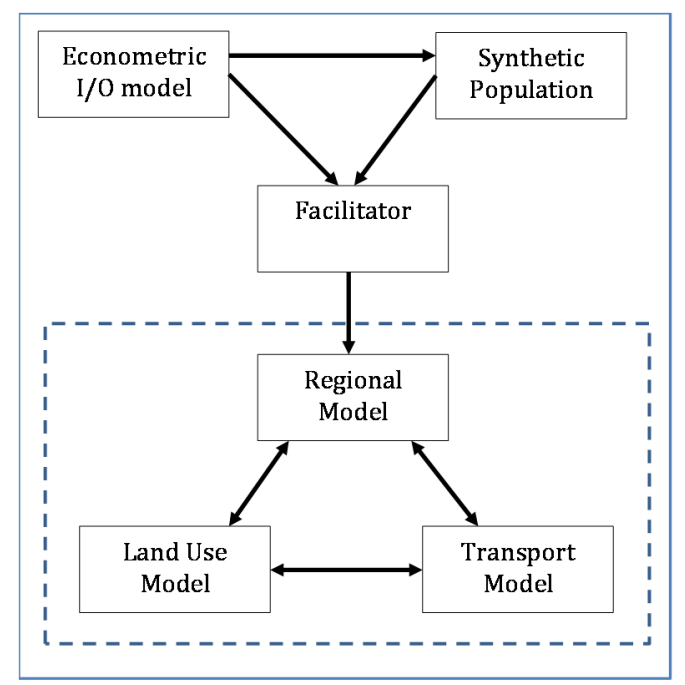

There are a number of tools that regional analysts apply to analyse and forecast the economy of a region. Two of the most commonly used tools are input-output (IO) modelling and econometric modelling. However, the standalone IO models are static and have restrictive assumptions of constant returns to scale. On the other hand, the econometric models lack the detailed sectoral disaggregation of IO models. As a result the integrated econometric input-output (EC-IO) modelling attempts to consider the timeline of the economy through time series in order to provide a more accurate picture of the dynamic characteristics of structural changes in a regional economy. In this research, we developed an integrated EC-IO model for the Illawarra region consisting of 19 economic sectors.

Figure 1. Current status of the model integration for Vision Illawarra. 
A synthetic population is a computational representation of the real population in the study area that matches the distribution of individuals and households as per the demographics from census data (Huynh et al., 2013). The algorithm constructing the initial population follows the sample-free approach and is among the very few in the literature that do not rely on a sample survey data to construct a synthetic population. The generator relies solely on aggregated demographic attributes of the target area (i.e. tables in census data) and is further constrained by biological laws (e.g. the mother-child age gap). The resulting population comes in the form of disaggregated records, each represents a synthetic individual characterised by several attributes such as age, gender, household relationship, household type, identification of the synthetic household he/she belongs to, and employment status. The evolution of the synthetic population (SP) involves the aging of each individual and the simulation of age-dependent life events (death, birth, divorce, and marriage). The occurrence of these life events influences both individuals as well as household entities, i.e. the consequent changes in the structure of households as a result of individual evolution are captured. Further details about synthetic population can be found in Huynh et al. (2013).

Regional model is based on the theory of spatial interaction that explains the flow of people, goods and services between two or more location in space (RIKS BV, 2005). Hence, it determines the migration of jobs and people between LGAs in the study area based on relative attractiveness of LGAs and the ease by which they can be reached. In addition, the regional model converts the number of jobs and number of people specified by the EC-IO and SP models into a land area requirement based on productivity in each LGA before passing the same down to the land use model for spatial allocation.

The constrained Cellular Automata (CA) based land use model in Metronamica has been used in many applications around the world, both in the original form and its variants (Wickramasuriya et al., 2009; Stanilov and Batty, 2011; van Vliet et al., 2012). The main variable of the land use model is a land use map in raster format which is iteratively updated in yearly time steps over the course of the simulation. The demands for the land are specified by the EC-IO model and the synthetic population, hence the land use model is constrained. The land use model then allocates this demand spatially. Land use transitions are driven by an endogenously calculated transition potential for which neighbourhood effect, physical suitability, accessibility (mainly to transport) and zoning contribute as key factors. A complete description of the land use model is available elsewhere (RIKS BV, 2015; Wickramasuriya et al., 2009).

The transport model is based on a classical four step approach (McNally, 2000), but has been made dynamic (RIKS BV, 2015). The land use model provides input to determine origins and destinations of trips, while the transport model influences land use change by means of accessibility, which is fed back to both the land use model and the regional model. This two-way communication provides the dynamic basis to the transport model.

Interaction between EC-IO and SP models is established via job-induced immigration and is based on heuristics. Individuals in the SP are labelled as 'in labour force' and 'not in labour force'. Individuals in the labour force are further categorized into employed and unemployed. If the EC-IO model predicts an increase in job numbers from one time step to the next, these additional jobs in the new time step can be assigned to one of three groups: unemployed local residents, outsiders who are willing to commute and outsiders who will migrate into the region (immigrants). Two parameters that determine the proportion of job allocation between these three categories then need to be calibrated.

The facilitator module is responsible for maintaining the communication between the EC-IO, SP the Regional model, Land use model and the transportation models. It is also responsible for coordinating the execution of five models. These models are run between 2006 and 2011. Outputs generated by the models for 2011 are compared against the observed data in 2011 for calibrating the models. Structural validation, face validation and expert judgements are used as validation techniques. Calibrated and validated models are expected to be used to explore a number of policy scenarios in the Illawarra region.

\section{RESULTS}

The forecasting component of the EC-IO model was tested and validated by comparing the forecasted values with the observed values available for our sample period. The impact analysis component of the model was tested and validated by comparison of the mean absolute percentage error for regional and national coefficients (Masouman \& Harvie, 2013). In this regard, a noticeable contribution was made by industry experts.

Synthetic population was validated by comparing the synthesized individuals and households against the Census data. Indices used for this comparison purpose includes the distribution of males and females by 
Wickramasuriya et al., Integrated modelling to aid strategic urban and regional planning

household relationship (Figure 2a) and the distribution of household types (Figure 2b). Overall, 16 household types were synthesised and these types are summarized in Table 1. Results show that the synthetic population very closely matches the observed data in the Census.

Table 1. Categories of household type in census data and their denotation in the synthetic population.

\begin{tabular}{|c|c|}
\hline Census data & $\begin{array}{c}\text { Denotation in } \\
\text { synthetic population }\end{array}$ \\
\hline Couple family with no children & HF1 \\
\hline \multicolumn{2}{|l|}{ Couple family with children under 15 and } \\
\hline dependent students and non-dependent children & HF2 \\
\hline dependent students and no non-dependent children & HF3 \\
\hline no dependent students and non-dependent children & HF4 \\
\hline no dependent students and no non-dependent children & HF5 \\
\hline \multicolumn{2}{|l|}{ Couple family with no children under 15 and } \\
\hline dependent students and non-dependent children & HF6 \\
\hline dependent students and no non-dependent children & HF7 \\
\hline no dependent students and non-dependent children & HF8 \\
\hline \multicolumn{2}{|l|}{ One parent family with children under 15 and } \\
\hline dependent students and non-dependent children & HF9 \\
\hline dependent students and no non-dependent children & HF10 \\
\hline no dependent students and non-dependent children & HF11 \\
\hline no dependent students and no non-dependent children & HF12 \\
\hline \multicolumn{2}{|l|}{ One parent family with no children under 15 and } \\
\hline dependent students and non-dependent children & HF13 \\
\hline dependent students and no non-dependent children & HF14 \\
\hline no dependent students and non-dependent children & HF15 \\
\hline Other family & HF16 \\
\hline Non family household & NF \\
\hline
\end{tabular}
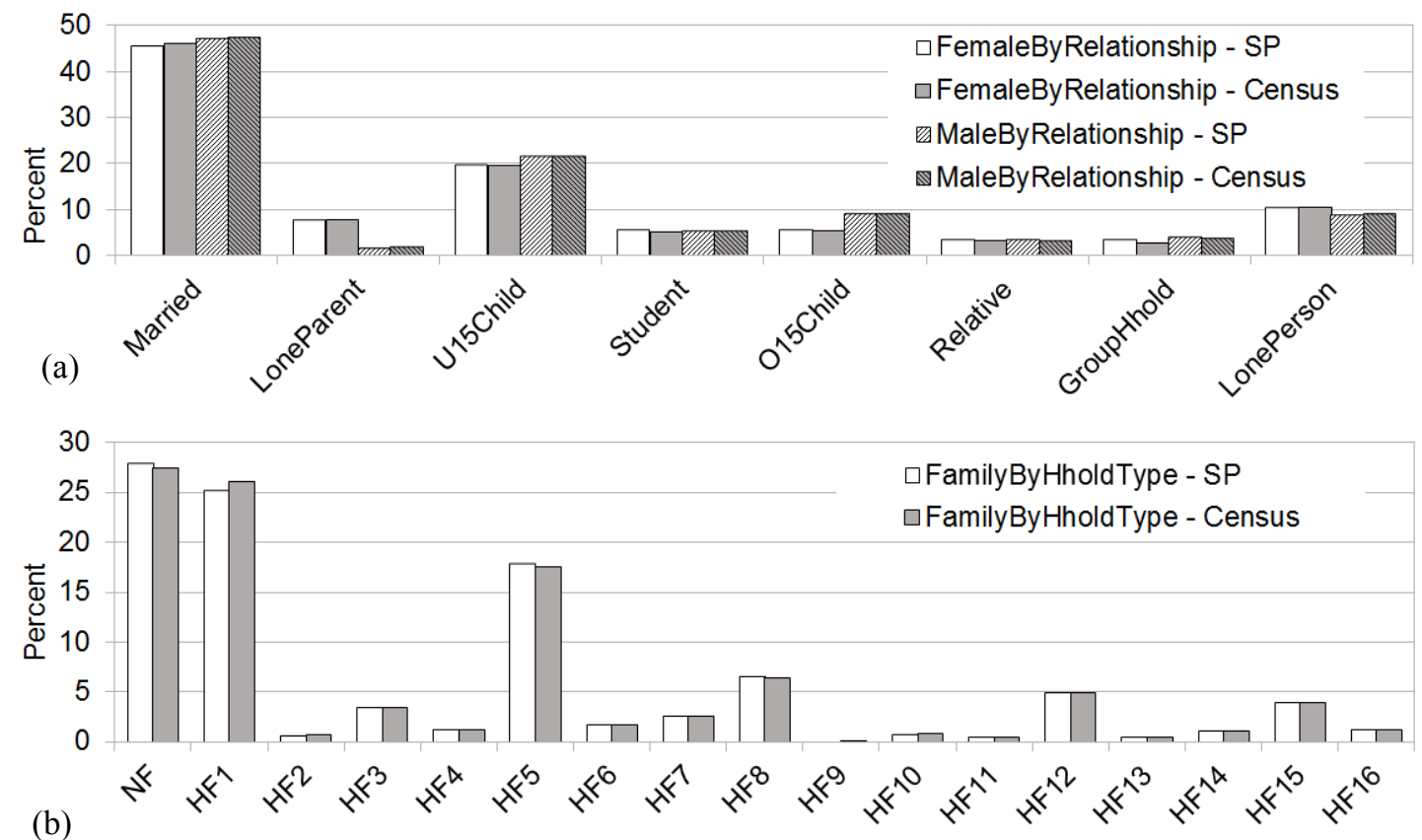

Figure 2. Validation of the synthetic population (a) distribution of males and females by household relationship, (b) distribution of households by household type. 
Calibration of the land use model was limited to only two land use classes namely, urban residential and industrial/commercial. The agreement between the observed and the simulated outputs is acceptable as evident by Kappa coefficients of 0.91 and 0.74 for urban residential and industrial/commercial land uses, respectively.

Performance of the transport model was established mainly by comparing observed and simulated OD matrices at an LGA level (Table 2 and 3). While the transport model has calculated correct magnitude in terms of the number of trips between all LGA pairs, the absolute difference between observed and simulated values calls for further calibration.

Table 2. Observed trip origin-destination matrix for transport mode 'car'.

\begin{tabular}{lrrr} 
Trips & \multicolumn{1}{c}{ D } & & \\
O & Kiama & Shellharbour & Wollongong \\
Kiama & 36369 & 11833 & 4919 \\
Shellharbour & 10322 & 132140 & 51671 \\
Wollongong & 7261 & 52781 & 565712
\end{tabular}

Table 3. Simulated trip origin-destination matrix for transport mode 'car'.

$\begin{array}{lrrr}\text { Trips } & \text { D } & & \\ \text { O } & \text { Kiama } & \text { Shellharbour } & \text { Wollongong } \\ \text { Kiama } & 24866 & 17786 & 10307 \\ \text { Shellharbour } & 16637 & 94960 & 60894 \\ \text { Wollongong } & 10679 & 64449 & 435528\end{array}$

The transport model records the speed at which vehicles move in the network during chosen time periods of the day for all simulated years. Figure 3 illustrates network speeds during morning peak on a typical weekday. Observed network speeds in Figure 3 are extracted from Google traffic maps. This comparison shows that the transport model is able to identify key network links that are subjected to significant congestions, thus adding to the confidence in using this model.

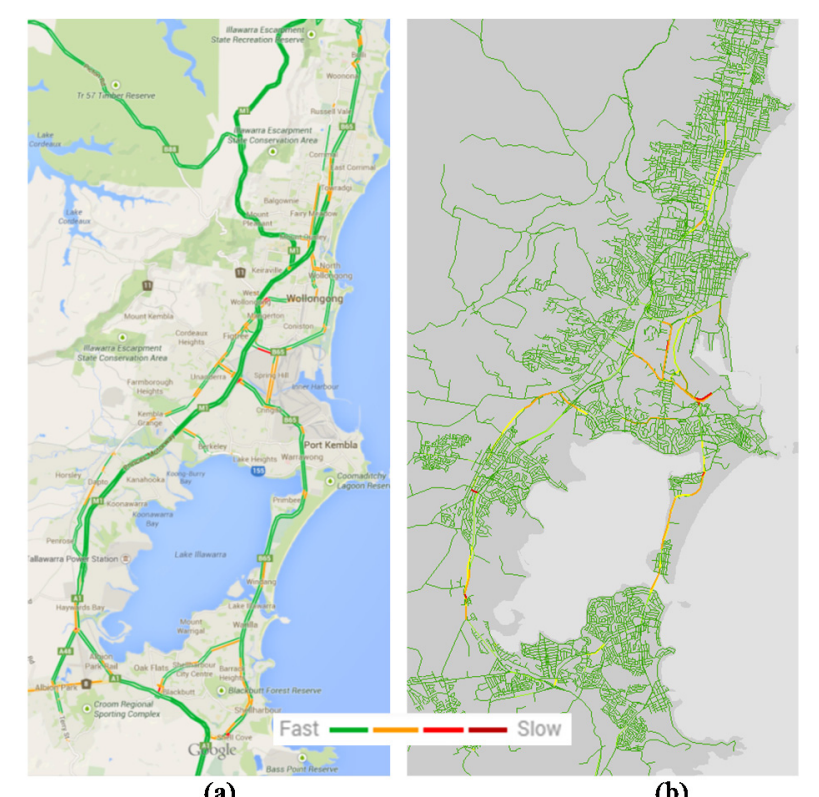

Figure 3. Traffic speed during morning peak on a weekday, (a) observed, (b) simulated. 
The calibrated and validated Vision Illawarra model is now being used to explore a number of land use, transportation, economic and demographic scenarios.

\section{CONCLUSION}

This paper discusses the ongoing development of a dynamic, integrated simulation model called Vision Illawarra. Vision Illawarra encompasses five interconnected models namely, an econometric input/output model, a synthetic population model, a land use model, a transport model and a spatial interaction model. Vision Illawarra can be used to support strategic decision making in urban landscapes as it will enable policy makers to explore the impact of their decisions on multiple dimensions of the urban fabric. Results from the calibration and validation give confidence to use Vision Illawarra for such purposes. The validated model is now being used to explore a number of policy scenarios affecting the study area, which is the Illawarra region of New South Wales, Australia.

However, the model is still being subjected to improvements. For example, the model, as it stands now, does not contain feedback loops from the synthetic population to the economic model and from the land use and transport models to the economic or the synthetic population models. We are in a process of establishing these feedback loops in the model. Moreover, we are integrating a geometric network-based utilities model to the Vision Illawarra model. Once complete, Vision Illawarra can be used to identify bottlenecks in existing utilities networks, particularly under various development scenarios. Lastly, we plan to replace the currentfour step transportation model with an agent-based transportation model to better utilise information captured in the synthetic population.

\section{ACKNOWLEDGEMENT}

Authors acknowledge the three City Councils of Wollongong, Shellharbour and Kiama, Sydney Water, REMONDIS, Endeavour Energy, Illawarra Chapter of the Property Council of Australia and the Illawarra Chamber of Commerce for the support they extended towards this project.

\section{REFERENCES}

Australian Bureau of Statistics. (2011). National Regional Profiles.

Geerlings, H. and Stead, D. (2003). The integration of land use planning, transport and environment in European policy and research, Transport Policy, 10(3), 187-196.

Hurkens, J., B.M. Hahn, and H. van Delden. (2008). Using the GEONAMICA software environment for integrated dynamic spatial modelling. In: M. Sànchez-Marrè, J. Béjar, J. Comas, A. Rizzoli and G. Guariso (Eds.) Proceedings of the iEMSs Fourth Biennial Meeting: Integrating Sciences and Information Technology for Environmental Assessment and Decision Making. International Environmental Modelling and Software Society, Barcelona, Spain.

Huynh, N., Namazi-Rad, M., Perez, P., Berryman, M. J., Chen, Q. \& Barthelemy, J. (2013). Generating a synthetic population in support of agent-based modeling of transportation in Sydney. 20th International Congress on Modelling and Simulation (MODSIM 2013), 1357-1363.

Masouman, A and Harvie, C. (2013). Development of Integrated Intersectoral-Time Series Strategies to Investigate the Economic Significance of Knowledge Sectors in the Illawarra, New South Wales, Proceedings of the 42nd Australian Conference of Economists.

McNally, M.G. (2000). The Four Step Model. In: Handbook of Transport Modelling, ed. David A. Hensher and Kenneth J. Button, 35-52.

van Delden, H., Hurkens, J. (2011). A generic Integrated Spatial Decision Support System for urban and regional planning, 19th International Congress on Modelling and Simulation: Perth, Australia.

Stanilov, K. and Batty, M., 2011, Exploring the Historical Determinants of Urban Growth Patterns through Cellular Automata, Transactions in GIS, 15(3), 253-271.

United Cities and Local Governments. (2010). Policy Paper on Strategic Urban Development, p. 6.

van Delden, H., Seppelt, R., White, R., and Jakeman, A.J. (2011). A methodology for the design and development of integrated models for policy support, Environmental Modelling \& Software, 26(3), 266279.

van Vliet, J., Hurkens, J., White, R. and van Delden, H. (2012). An activity-based cellular automaton model to simulate land-use dynamics, Environment and Planning B-Planning \& Design, 39(2), 198-212.

Wickramasuriya, R. C., Bregt, A. K., van Delden, H. and Hagen-Zanker, A. (2009). The dynamics of shifting cultivation captured in an extended Constrained Cellular Automata land use model, Ecological Modelling, 220(18), 2302-2309. 